\title{
PERSEPSI GURU TERHADAP PEMBELAJARAN MENGGUNAKAN KELAS DIGITAL
}

\author{
Abd. Ghofur ${ }^{1}$, Evi Aulia Rachma ${ }^{2}$ \\ 1,2Universitas PGRI Adi Buana, Kampus Lamongan \\ e-mail: 1ghofurkita@yahoo.com, eviauliarachma134@gmail.com
}

\begin{abstract}
Abstrak
Penelitian ini bertujuan untuk mengidentifikasi persepsi guru SD terhadap pembelajaran menggunakan kelas digital google classroom. Penelitian ini melibatkan 50 guru SD kelas IV seKecamatan Lamongan. Analisa data yang digunakan dalam penelitian ini adalah analisa deskriptif kuatitatif. Berdasarkan hasil penelitian dapat disimpulkan bahwa sebanyak $90 \%$ guru menyatakan perlu mengikuti pelatihan tentang pembelajaran menggunakan kelas digital. Sebanyak $74 \%$ guru menyatakan perlu menerapkan pembelajaran dengan menggunakan kelas digital google classroom. Google classroom bersifat fleksibel, jadi siswa dapat belajar sewaktuwaktu diluar jam sekolah. Berdasarkan hal tersebut sebanyak $86 \%$ guru menyatakan perlu menyediakan bahan belajar bagi siswa yang bisa diakses atau digunakan sewaktu-waktu diluar jam sekolah melalui google classroom. Sebanyak $76 \%$ guru menyatakan bahwa google classroom membuat guru lebih inovatif dalam menyajikan materi pembelajaran. Kemudian sebanyak $78 \%$ guru menyatakan bahwa penggunaan google classroom memudahkaan guru dalam proses penilaian tugas-tugas siswa.
\end{abstract}

Kata Kunci: Persepsi Guru, Kelas Digital

\begin{abstract}
This study aims to identify elementary school teachers' perceptions of learning using the digital classroom google classroom. This research involved 50 elementary grade IV teachers in Lamongan District. Analysis of the data used in this study is a descriptive quantitative analysis. Based on the results of the study it can be concluded that as many as $90 \%$ of teachers stated that they needed to attend training on learning using digital classes. As many as $74 \%$ of teachers said that they needed to implement learning by using digital classroom google classroom. Google classroom is flexible, so students can study at any time outside of school hours. Based on this, $86 \%$ of teachers stated that they needed to provide learning materials for students that could be accessed or used at any time outside of school hours through Google classroom. As many as $76 \%$ of teachers stated that google classroom made teachers more innovative in presenting learning materials. Then as many as $78 \%$ of teachers stated that the use of google classroom facilitated teachers in the process of assessing student assignments.
\end{abstract}

Keywords: teachers' perception, digital classrooms

\section{Pendahuluan}

Pemanfaatan internet kini telah merambah berbagai aktivitas kehidupan, tidak terkecuali di dunia pendidikan. Apalagi di era digital ini, hampir semua bidang kehidupan tak lepas dari penggunaan internet, tak terkecuali aktivitas pendidikan. Apalagi di masa pandemi covid 19 yang melarang terjadinya aktivitas berkerumun banyak orang, menambah pentingnya 
penggunaan internet di masyarakat. Keberadaan internet menjadikan dunia semakin dekat dan terjangkau oleh ruang dan waktu. Dalam dunia pendidikan internet menjadi media yang sangat ideal untuk melakukan kegiatan pembelajaran jarak jauh. Penggunaan internet dapat menghubungkan peserta didik dengan pendidik, melihat jadwal pembelajaran, mengerjakan tugas, melihat nilai, konsultasi, dan melakukan diskusi secara maya. Bagi para pengajar, internet bermanfaat mengembangkan profesinya, sebab dapat : (a) meningkatkan pengetahuan, (b) berbagi sumber dengan rekan sejawat, (c) berkolaborasi dengan lintas pengajar di luar instansinya, (d) kesempatan mempublikasikan informasi secara langsung, (e) mengatur komunikasi secara teratur, dan (f) berpartisipasi dalam forum-forum lokal maupun intemasional [1].

Kehadiran internet dapat menawarkan hal baru dalam aktivitas pembelajaran. Penggunaan teknologi memberikan dampak positif dalam pembelajaran[2]. Di era digital saat ini, guru memiliki banyak pilihan media pembelajaran interaktif yang dapat menunjang proses pembelajaran. Teknologi dan media bisa berperan banyak untuk belajar. Teknologi dan media digunakan untuk mendukung penyajian pengajaran apabila pengajarannya berpusat pada guru. Peserta didik merupakan pengguna utama teknologi dan media apabila pengajaran berpusat pada peserta didik. Penggunaan teknologi informasi menjadikan kegiatan pembelajaran disekolah menjadi lebih menarik, aktif, dan kreatif. Tujuannya untuk mendorong pembelajaran yang efektif dan efisien [3]. Hal tersebut sebagaimana tercantum dalam Peraturan Menteri Pendidikan dan Kebudayaan No.65 tahun 2013 tentang pemanfaatan teknologi informasi untuk meningkatkan efisiensi dan efektifitas pembelajaran.

Teknologi saat ini mengharuskan guru menerapkan pola pengajaran digitalisasi. Dalam rangka mensinergikan proses modernisasi dan kualitas pembelajaran, maka perlu adanya perubahan paradigma yang dilakukan oleh guru dalam melaksanakan proses pembelajaran di sekolah. Penggunaan internet dan teknologi multimedia mampu merombak cara penyampaian pengetahuan dan dapat menjadi alternatif pembelajaran yang dilaksanakan dalam kelas tradisional [11]. Proses pembelajaran saat ini akan banyak dilakukan secara daring (online) menggunakan teknologi. Guru harus mampu menguasai dan mengoperasikan teknologi informasi serta mengaplikasikannya dalam pembelajaran di kelas. Pengaplikasian pembelajaran daring ini adalah bukti dari revolusi industry 4.0, dimana pengaksesan teknologi tidak terbatas, sehingga memungkinkan pelaksanaan pembelajaran daring atau jarak jauh [10]. Banyak media yang dapat digunakan guru untuk mendukung pelaksanaan pembelajaran secara online. Misalnya kelas-kelas virtual menggunakan layanan Google Classroom, Edmodo, dan Schoology dan aplikasi pesan instan seperti WhatsApp [8\&9].

Google classroom merupakan salah satu aplikasi yang dapat membantu para guru mewujudkan komunikasi yang efektif antara siswa dan guru. Selain aplikasi tersebut bisa diakses secara mudah juga tanpa biaya. Google classroom merupakan salah satu media pendidikan yang telah disediakan gratis oleh google [12]. Pemanfaatan google classroom bisa melalui komputer dan gawai yang bisa dilakukan kapan saja dan dimana saja selama memiliki akses internet. Karena kemudahan dalam penggunaan aplikasi ini, menjadi pilihan banyak guru dalam mengimplementasikan pembelajaran jarak jauh. Jika menggunakan gawai guru dan siswa dapat mengunduh aplikasi melalui playstore di android atau melalui app store di IOS dengan keyword google classroom. Jika menggunakan komputer atau laptop guru dan siswa dapat mengunjungi situs https://classroom.google.com. Tujuan pembelajaran akan mudah direalisasikan dan sarat kebermaknaan dengan penerapan google classroom. Penggunaan aplikasi google classroom dapat mempermudah guru dalam mengelola pembelajaran dan menyampaikan informasi secara tepat dan akurat kepada peserta didik [4]. 


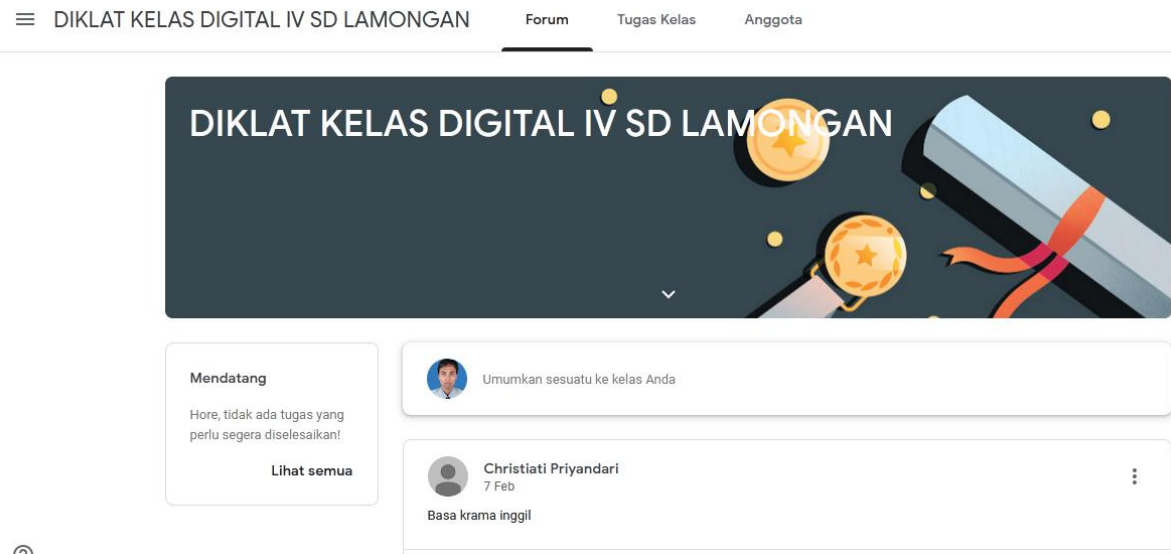

Gambar 1. Tampilan Google Classroom

Fitur komunikasi yang ada dalam aplikasi google classroom dapat digunakan sebagai media pembelajaran sekaligus sebagai sarana komunikasi yang efektif antara guru dan siswa. Pada kelas digital tersebut, ada fitur forum, tugas kelas dan anggota. Pada fitur forum guru bisa mengupload materi, berdiskusi dan menyampaikan apa yang menjadi pembahasan dalam setiap kali pertemuan. Sedangkan pada fitur tugas kelas bisa digunakan untuk memberi tugas kepada siswa, baik dalam bentuk kuis maupun tugas lainnya. Kemudian pada fitur anggota berisi seluruh peserta yang mengikuti kelas digital tersebut.

Guru perlu memiliki pengetahuan dan keterampilan tentang komunikasi efektif melalui media pembelajaran google classroom, sehingga kualitas pengajaran dapat lebih baik. Tidak semua guru mengaplikasikan google classroom sebagai media pembelajaran dikelas. Salah satu penyebabnya yaitu kompetensi guru dalam penguasaan penguasaan teknologi informasi \& komunikasi (TIK) masih sangat terbatas. Berdasarkan latar belakang tersebut, maka penelitian ini betujuan untuk menganalisis persepsi guru SD terhadap pembelajaran menggunakan kelas digital google classroom.

\section{Metode Penelitian}

Pada penelitian ini digunakan metode penelitian survei deskriptif dengan menggunakan pendekatan kuantitatif. Penelitian ini melibatkan 50 orang guru perwakilan 25 sekolah dasar kelas empat se-Kecamatan Lamongan dengan pengambilan sample menggunakan teknik purposive sampling.

Adapun sekolah dasar yang terlibat dalam penelitian ini sebagaimana tersaji dalam tabel 1 sebagai berikut:

Tabel 1. Sekolah dasar yang yang menjadi subyek penelitian

\begin{tabular}{cll}
\hline No. & Nama Satuan Pendidikan & Status \\
\hline 1 & SD Islam Plus Al Mudhofar & Swasta \\
\hline 2 & SD Kemala Bhayangkari 5 & Swasta \\
\hline 3 & SD Negeri 1 Kramat & Negeri \\
\hline 4 & SD Negeri 1 Made & Negeri \\
\hline 5 & SD Negeri 1 Rancangkencono & Negeri \\
\hline 6 & SD Negeri 1 Sendangrejo & Negeri \\
\hline 7 & SD Negeri 1 Sidoharjo & Negeri \\
\hline 8 & SD Negeri 1 Sukomulyo & Negeri \\
\hline 9 & SD Negeri 1 Tumenggungan & Negeri \\
\hline
\end{tabular}




\begin{tabular}{lll}
\hline 10 & SD Negeri 2 Kramat & Negeri \\
\hline 11 & SD Negeri 2 Rancangkencono & Negeri \\
\hline 12 & SD Negeri 2 Sendangrejo & Negeri \\
\hline 13 & SD Negeri 2 Sukomulyo & Negeri \\
\hline 14 & SD Negeri 2 Sukorejo & Negeri \\
\hline 15 & SD Negeri 2 Tumenggungan & Negeri \\
\hline 16 & SD Negeri 3 Jetis & Negeri \\
\hline 17 & SD Negeri 4 Made & Negeri \\
\hline 18 & SD Negeri Banjar Mendalan & Negeri \\
\hline 19 & SD Negeri Karanglangit & Negeri \\
\hline 20 & SD Negeri Kebet & Negeri \\
\hline 21 & SD Negeri Kepatihan & Negeri \\
\hline 22 & SD Negeri Pangkatrejo & Negeri \\
\hline 23 & SD Negeri Plosowahyu & Negeri \\
\hline 24 & SD Negeri Sidomukti & Negeri \\
\hline 25 & SD Negeri Sumberjo &
\end{tabular}

Instrumen pengumpulan data dengan kuesioner, wawancara, observasi dan dokumentasi. Teknik pengumpulan data yang digunakan dalam penelitian ini yaitu angket tertutup untuk mendapatkan data primer mengenai persepsi guru SD terhadap pembelajaran dengan menggunakan kelas digital google classroom. Analisa data yang digunakan dalam penelitian ini adalah analisa deskriptif kuatitatif. Penyajian data dibuat dalam bentuk deskriptif yang bertujuan memberikan deskripsi mengenai subyek penelitian berdasarkan data dari variabel yang diperoleh dari kelompok subyek yang diteliti dengan menggunakan tehnik tabulasi, dengan menyajikan hasil penelitian tabel/bagan/grafik distribusi frekuensi dengan persentase untuk masing-masing kelompok.

\section{Hasil dan Pembahasan}

\section{Metode Pembelajaran yang Digunakan Guru}

Berdasarkan hasil penelitian, sebanyak $60 \%$ guru SD kelas 4 menggunakan metode pembelajaran PAIKEM. Sedangkan $30 \%$ guru lainnya menggunakan metode pembelajaran ceramah. Kemudian sebanyak $10 \%$ guru menggunakan metode pembelajaran secara blended learning. Pembelajaran PAIKEM merupakan pembelajaran aktif, inovatif, efektif dan menyenangkan. Penggunaan metode pembelajaran dengan ceramah cenderung membuat siswa merasa bosan. Agar tidak membosankan penyampaian metode ceramah dapat divariasikan dengan metode-metode pebelajaran yang lain. Sedangkan metode blended learning adalah metode pembelajaran yang menggabungkan antara metode konvensional /tatap muka dengan pembelajaran online. Setiap metode pembelajaran harus mengandung rumusan pengorganisasian bahan pelajaran, strategi penyampaian, dan pengelolaan kegiatan dengan memperhatikan faktor tujuan belajar, karakteristik peserta didik, hambatan belajar, agar dapat diperoleh efisiensi, efektivitas, dan daya tarik pembelajaran [5]. Untuk mengetahui secara detail metode pembelajaran yang digunakan oleh guru bisa dilihat pada gambar 2 di bawah ini. 


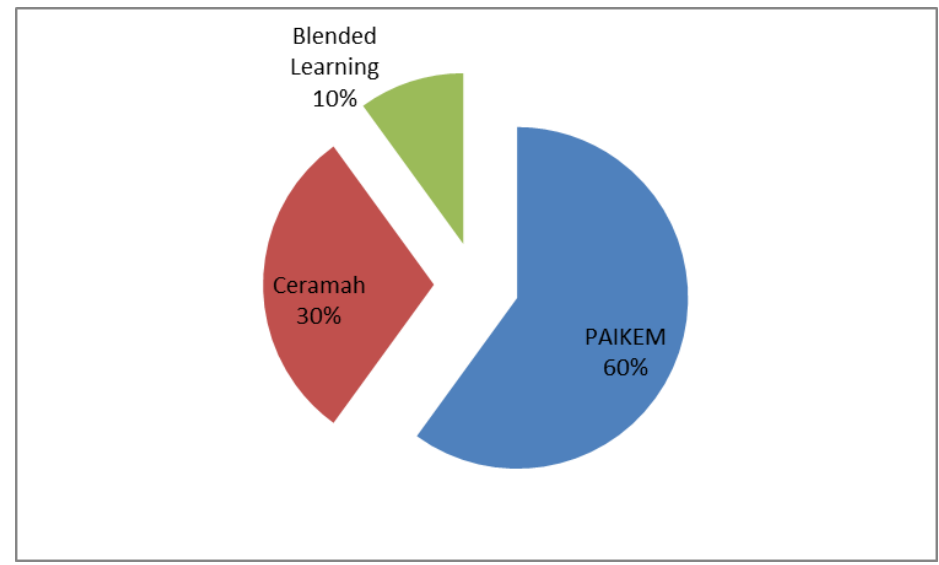

Gambar 2. Metode Pembelajaran yang digunakan

\section{Guru perlu meng-upgrade metode pembelajaran sesuai perkembangan teknologi}

Guru harus mengupgrade ilmu dan keterampilan. Guru di era milenial dan revolusi industri dituntut memiliki skill dalam menguasai teknologi informasi. Guru perlu meng-upgrade metode pembelajaran sesuai perkembangan teknologi. Berdasarkan penelitian, sebanyak $100 \%$ guru SD mengatakan perlu meng-upgrade metode pembelajaran. Guru dituntut untuk kreatif dan inovatif agar siswa tidak bosan dan tertinggal (seperti pada gambar 3).

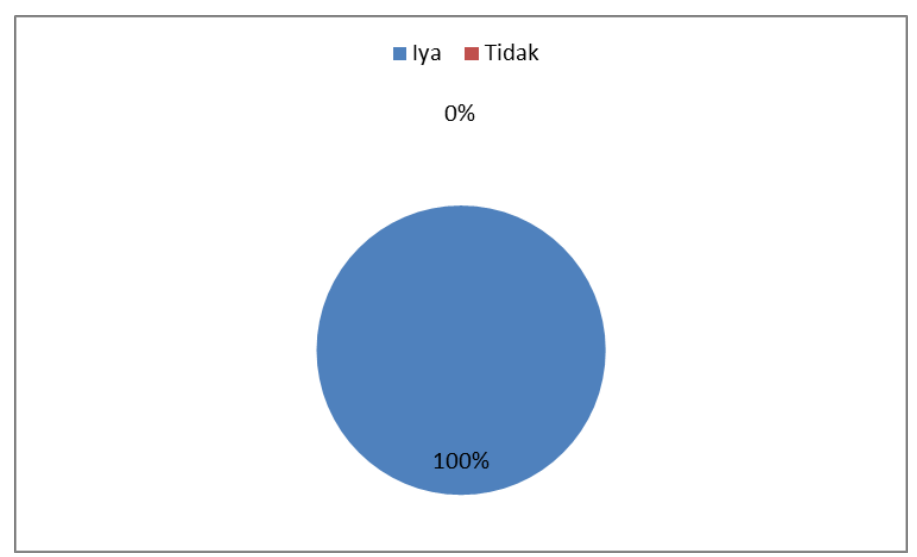

Gambar 3. Meng-upgrade metode pembelajaran

Paradigma pembelajaran telah bergeser dari pembelajaran tradisional menuju pembelajaran berbasis digital di era perkembangan Teknologi Informasi dan Komunikasi saat ini. Perubahan sumber dan bahan ajar yang biasanya menggunakan papan tulis dan spidol berganti dengan penggunaan media seperti laptop, LCD Projector dan sebagainya. Penggunaan material pembelajaran seperti buku, modul dan lembar kerja siswa berganti dengan youtube, $e$ book maupun situs internet. Metode pembelajaran konvensional melalui metode ceramah di depan kelas berganti dengan pembelajaran berbasis digital dengan memanfaatkan fasilitas seperti e-mail, aplikasi Android melalui gadget dan HP, multimedia interaktif dan lain lain.

\section{Guru perlu mengikuti pelatihan atau kegiatan sejenisnya tentang pembelajaran menggunakan kelas digital}

Berdasarkan penelitian, sebanyak $90 \%$ guru menyatakan perlu mengikuti pelatihan atau kegiatan sejenisnya tentang pembelajaran menggunakan kelas digital. Kemudian sebanyak $10 \%$ guru menyatakan tidak perlu (seperti pada gambar 4). 


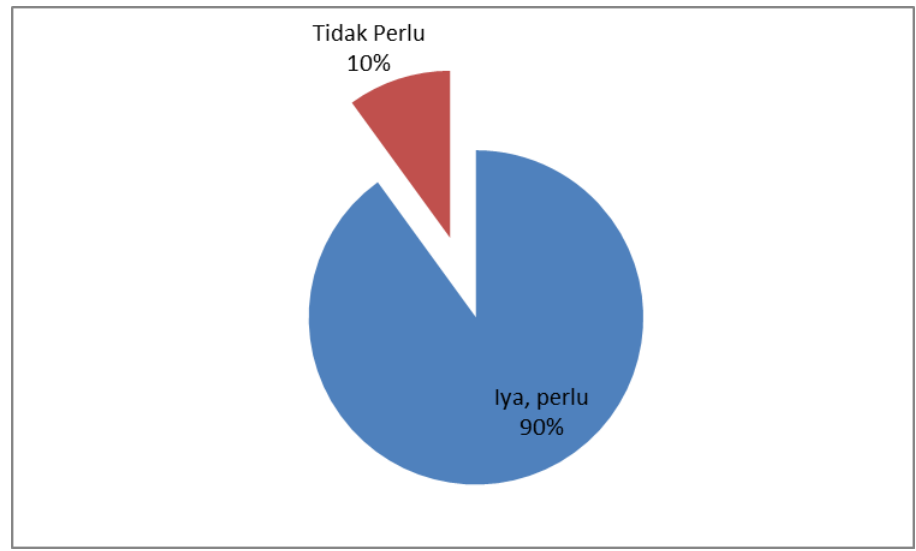

Gambar 4. Mengikuti Pelatihan Kelas digital

Selain itu, berdasarkan hasil penelitian, sebanyak $54 \%$ guru mengatakan belum pernah ikut pelatihan kelas digital. Sedangkan sebanyak $46 \%$ guru mengatakan pernah mengikuti pelatihan kelas digital $1 \mathrm{~s} / \mathrm{d} 2$ kali. Guru dituntut harus bisa beradaptasi dengan kemajuan teknologi. Di era Revolusi Industri 4.0, para guru diharapkan bisa menerapkan pola pengajaran digitalisasi dalam kelas. Kompetensi guru dalam penguasaan Teknologi Informasi dan Komunikasi (TIK) masih sangat terbatas, padahal guru harus mampu menguasai dan mengoperasikan teknologi informasi serta mengapliaksikannya dalam pembelajaran di kelas. Untuk itu guru perlu mengikuti pelatihan menggunakan kelas digital google classroom (seperti pada gambar 5 di bawah ini).

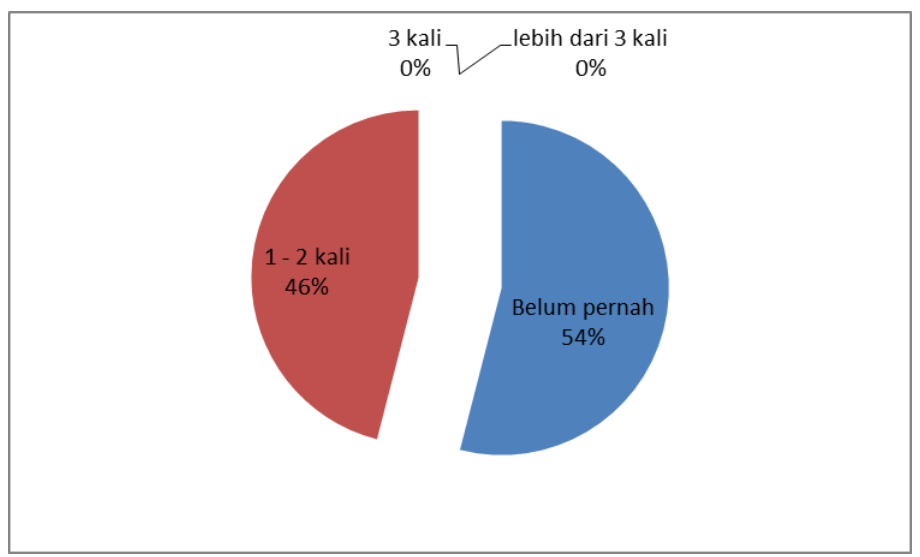

Gambar 5. Frekuensi banyaknya guru mengikuti pelatihan kelas digital

Pelatihan ini bertujuan untuk mengenalkan dan melatih guru dalam menggunakan pembelajaran kelas digital (digital class) dalam proses pembelajaran. Kelas digital (digital class) dapat dimanfaatkan guru baik dalam perencanaan pembelajaran, pelaksanaan pembelajaran, dan evaluasi proses pembelajaran tanpa harus bertatap muka dengan siswa.

\section{Guru perlu menerapkan pembelajaran dengan menggunakan kelas digital google classroom}

Berdasarkan penelitian, sebanyak $74 \%$ guru menyatakan perlu menerapkan pembelajaran dengan menggunakan kelas digital google classroom. Kemudian sebanyak $26 \%$ guru menyatakan tidak perlu (seperti pada gambar 6). 


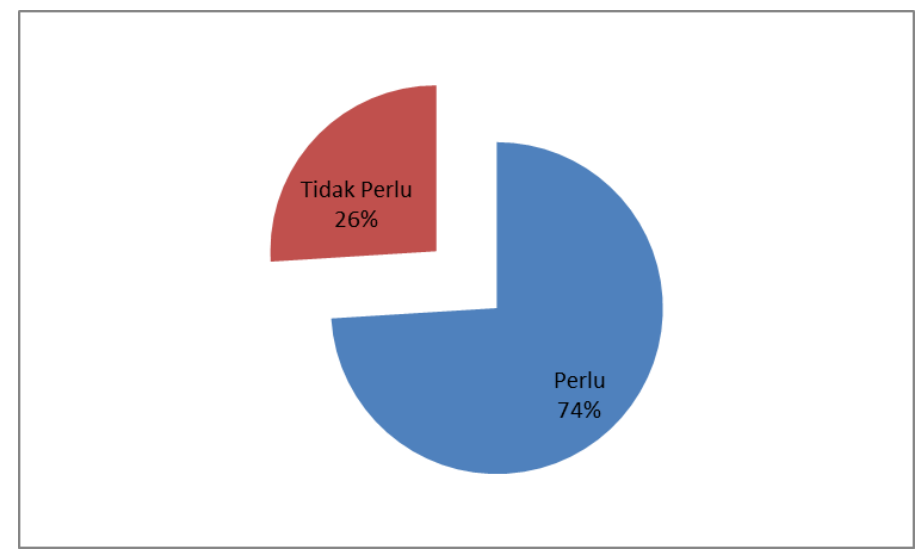

Gambar 6. Menerapkan Pembelajaran menggunakan google classroom

Dunia pendidikan saat ini sudah mulai mengarah kepada pembelajaran yang mengarah kepada pembelajaran secara daring (online). Google classroom merupakan salah satu cara yang dapat digunakan guru dalam proses pembelajaran secara daring (online). Pemanfaatan Google Classroom dapat melalui melalui komputer dan gawai. Jika menggunakan gawai guru dan siswa dapat mengunduh aplikasi melalui playstore di android atau melalui app store di IOS dengan keyword google classroom. Jika menggunakan komputer atau laptop guru dan siswa dapat mengunjungi situs https://classroom.google.com. Google classroom dapat digunakan secara gratis dan dapat dimanfaatkan dalam proses pembelajaran sesuai kebutuhan. Guru dapat mengelola kelas dengan efektif dan efisien menggunakan google classroom [6].

Pendidikan saat ini tidak dapat dipisahkan dengan adanya teknologi, dimana semua hal itu harus sejalan. Namun dalam proses pembelajaran guru tidak sepenuhnya menggunakan pembelajaran secara digital, pembelajaran konvensional juga tetep dibutuhkan. Pembelajaran konvensional akan lebih menarik apabila divariasikan dengan metode pembelajaran yang lain [16], [17]. Untuk itu blended learning menjadi salah satu solusi yang bisa dilaksanakan oleh guru dalam pembelajaran. Menurut Thorne blended learning adalah kesempatan untuk mengintegrasikan inovasi dan teknologi yang ditawarkan oleh pembelajaran daring dengan interaksi dan partisipasi pembelajaran konvensional. Kegiatan blended learning ditandai dengan menggabungkan pembelajaran konvensional dan daring. Penggabungan pembelajaran disesuikan dengan tujuan pembelajaran yang hendak dicapai [7].

Guru perlu menyediakan bahan belajar untuk siswa yang bisa diakses atau digunakan
sewaktu-waktu diluar jam sekolah melalui kelas digital google classroom

Berdasarkan hasil analisis data penelitian, diketahui bahwa sebanyak $86 \%$ guru menyatakan perlu menyediakan bahan belajar untuk siswa yang bisa diakses/digunakan sewaktu-waktu diluar jam sekolah melalui kelas digital google classroom. Sedangkan sebanyak $14 \%$ guru menyatakan tidak perlu. Pembelajaran dengan penggunaan google classroom memiliki kelebihan untuk mempermudah guru dan siswa dalam pembelajaran. Guru dapat membuat dan mengelola kelas, memberikan tugas serta menilai maupun memberi masukan secara langsung. Kemudian siswa dapat memantau materi dan tugas kelas yang diberikan guru (seperti pada gambar 7). Selain itu siswa dapat berbagi materi dan berinteraksi dalam kelas atau melalui email, mengirim tugas dan mendapatkan masukan nilai secara langsung. Google classroom mudah digunakan, menghemat waktu, berbasis cloud, fleksibel, dan gratis [8]. Kelebihan dari google classroom adalah dapat melakukan pembelajaran secara daring bersama anggota kelas yang ada, guru dapat memberikan materi pembelajaran berupa power point, word, excel maupun berbentuk video [13], [14]. Untuk mengetahui lebih detail bisa dilihat pada gambar 7 di bawah ini. 


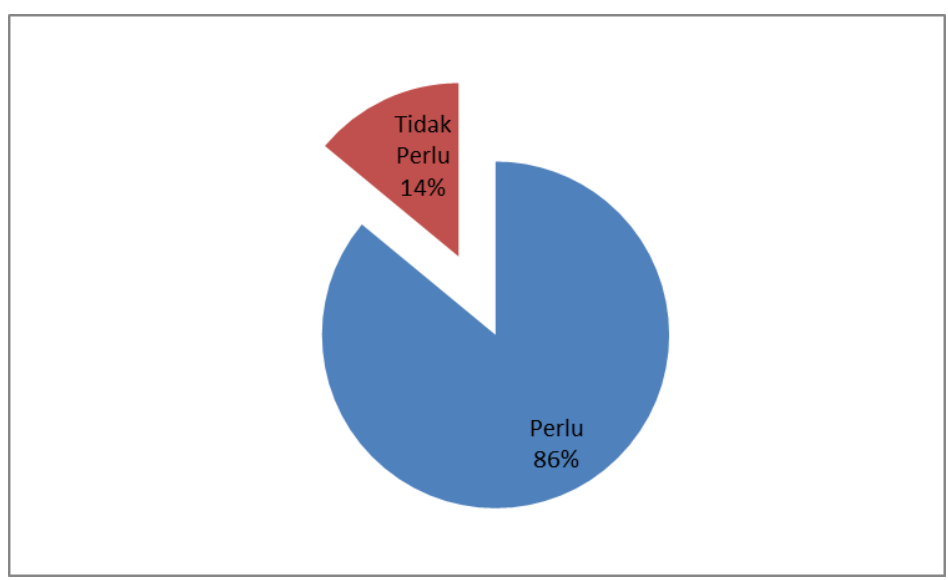

Gambar 7. Menyediakan bahan belajar di google classroom

\section{Google classroom membuat guru lebih kreatif dan inovatif dalam menyajikan materi pembelajaran}

Berdasarkan hasil penelitian, sebanyak $76 \%$ guru menyatakan bahwa google classroom membuat guru lebih inovatif dalam menyajikan materi pembelajaran. Sedangkan $24 \%$ guru menyatakan google classroom tidak membuat guru lebih inovatif Guru dapat menyajikan materi pembelajaran dalam bentuk word ataupun pdf dan video melalui google classroom (seperti pada gambar 8).

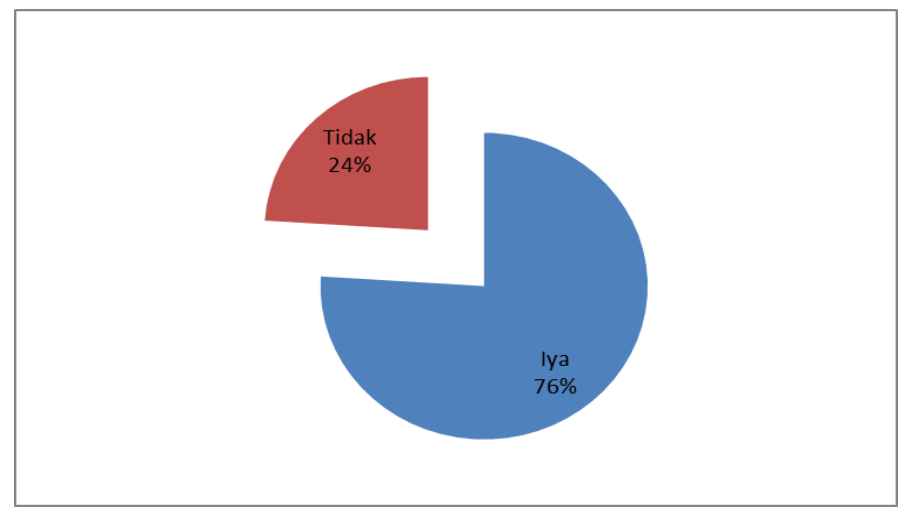

Gambar 8. Google Classroom membuat guru lebih inovatif

Guru dituntut lebih kreatif dan inovatif dalam menyajikan materi pembelajaran. Jika biasanya guru hanya ceramah didepan siswanya, saat kini guru bisa memanfaatkan teknologi untuk kegiatan belajar mengajar. Cara pengajaran yang monoton dan konvensional dianggap kurang menarik dan tidak efektif dalam menarik minat belajar siswa. Google Classroom dapat digunakan guru dengan efektif dan efisien dalam pengelolaan kelas [15]. Model pembelajaran yang interaktif dapat membangkitkan minat maupun motivasi siswa dalam belajar. selain itu dapat memberikan kesempatan bagi siswa untuk memberikan tanggapannya terhadap materi yang disampaikan.

\section{Penggunaan kelas digital google classroom memudahkan guru dalam proses penilaian tugas-tugas siswa}

Berdasarkan hasil penelitian, sebanyak $78 \%$ guru menyatakan bahwa penggunaan google classroom memudahkaan guru dalam proses penilaian tugas-tugas siswa. Kemudian 
sebanyak $22 \%$ guru lainnya menyatakan tidak. Guru dapat membuat dan mendistribusikan materi maupun tugas-tugas untuk siswa secara online. Kemudian guru dapat menentukan peringkat, memberikan umpan balik untuk semua tugas yang dikerjakan siswa. setelah itu guru dapat melakukan penilaian secara langsung menggunakan aplilasi google classroom (seperti pada gambar 9). Hal tersebut sesuai dengan peelitian yang dilakukan oleh Iftakhar dengan judul Google Classroom: What Works and How? dalam penelitian tersebut dikatakan bahwa google classroom dapat membantu untuk memonitoring siswa dalam belajar. Guru dapat melihat seluruh aktivitas siswa selama pembelajaran berlangsung di google classroaom. Interaksi antara guru dan siswa terekam dengan baik dengan aplikasi google classroom [8].

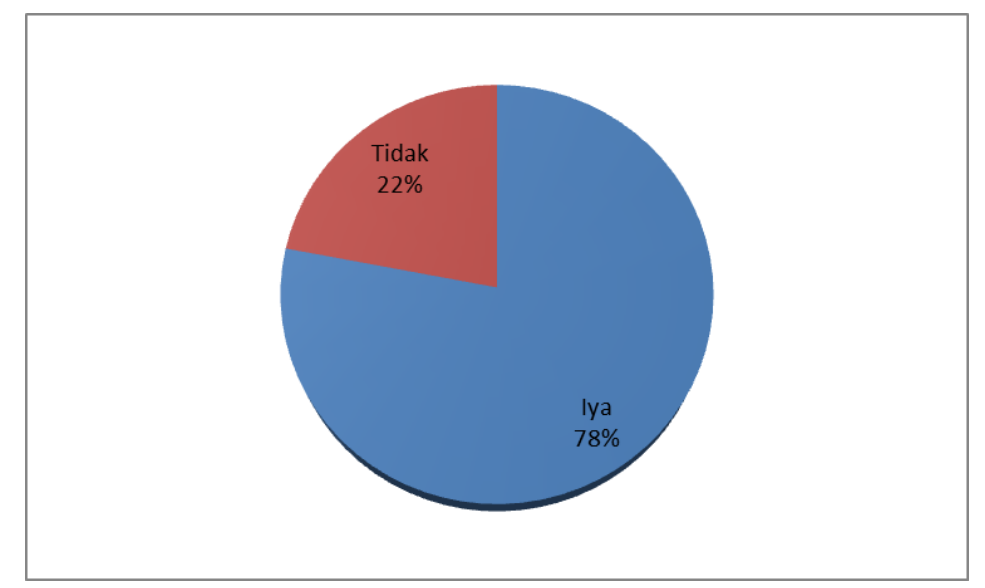

Gambar 9. Google classroom memudahkan proses penilaian tugas

\section{Kesimpulan}

Berdasarkan hasil pembahasan dapat disimpulkan bahwa media pembelajaran google classroom dapat digunakan guru dalam proses pembelajaran secara daring (online). Google classroom bersifat fleksibel, jadi siswa dapat belajar sewaktu-waktu diluar jam sekolah. Berdasarkan hal tersebut sebanyak $86 \%$ guru menyatakan perlu menyediakan bahan belajar bagi siswa yang bisa diakses atau digunakan sewaktu-waktu diluar jam sekolah melalui google classroom. Sebanyak $76 \%$ guru menyatakan bahwa google classroom membuat guru lebih inovatif dalam menyajikan materi pembelajaran. Kemudian sebanyak $78 \%$ guru menyatakan bahwa penggunaan google classroom memudahkaan guru dalam proses penilaian tugas-tugas siswa.

Selain mengikuti pelatihan pembelajaran menggunakan kelas digital, guru juga harus konsisten dalam penggunaan google classroom. Hal ini dimaksudkan agar guru lebih terampil dan kreatif lagi dalam mengggunakan media pembelajaran secara digital. Selain itu penggunaan google classroom harus didukung dengan ketersedian koneksi internet yang baik. Untuk itu sekolah harus menyediakan fasilitas intenet untuk memudahkan dalam penggunaan google classroom. Sehingga, sinergi yang baik dibutuhkan tidak hanya kreatifitas guru akan tetapi fasilitas juga harus sejalan demi tercapainya kualitas pembelajaran yang lebih baik lagi.

\section{Daftar Pustaka}

[1] Sutirman. (2006). Pemanfaatan Internet dalam Dunia Pendidikan. Efisiensi: Kajian Ilmu Administrasi. 3(6), 199-208.

[2] Megahantara, G.S. (2017). Pengaruh teknologi terhadap pendidikan di abad 21. Yogyakarta: Universitas Negeri Yogyakarta.

[3] Smaldino, S.E., Lowther, D.L. \& Russell, J.D., (2008). Instructional technology and media for learning 
[4] Hakim, A.B., (2016). Efektifitas Penggunaan E-Learning Moodle, Google Classroom Dan Edmodo. I-STATEMENT: Information System and Technology Management, 2(1).

[5] Miarso, Y., (2004). Menyemai benih teknologi pendidikan, Kencana.

[6] Azhar, K. A., \& Iqbal, N. (2018). Effectiveness of Google Classroom: Teachers' Perceptions Effectiveness of Google Classroom : Teachers'. Prizren Social Science Journal, 2(2), 1-16.

[7] Sjukur, S.B. (2012). Pengaruh Blended Learning terhadap Motivasi Belajar dan Hasil Belajar Siswa Tingkat SMK. Jurnal Pendidikan Vokasi, 3 (2), 368-378.

[8] Iftakhar, Shampa. (2016). Google Classroom: What Works and How?. Journal of Education and Social Sciences, 3 (feb), 12-18.

[9] Sicat, A. S. (2015). Enhancing College Students' Proficiency in Business Writing Via Schoology. International Journal of Education and Research. 3(1), 159-178

[10] Verawardina, U., \& Jama, J. (2018). Philosophy TVET di era derupsi revolusi industri 4.0 di Indonesia. Jurnal Filsafat Indonesia, 1(3), 104-111.

[11] Zhang, D., Zhao, J. L., Zhou, L., \& Nunamaker, J. F. (2004). Can e-learning replace classroom learning?. Communications of the ACM. 47(5), 74-79

[12] Irsalina Savitri, D. (2019). Penggunaan Pembelajaran 4.0 Berbantuan Aplikasi Google Classroom Dan Google Form Dalam Mata Kuliah Ilmu Sosial Budaya Dasar 4.0. Jurnal Borneo Sintek, 2(1), 20-25.

[13] Fitriningtiyas, D. A., Umamah, N., \& Sumardi. (2019). Google classroom: As a media of learning history. IOP Conference Series: Earth and Environmental Science, 243(1).

[14] Soni, S., Hafid, A., Hayami, R., Fatma, Y., Wenando, F. A., Amien, J. Al, ... Hasanuddin, H. (2018). Optimalisasi Penggunaan Google Classroom, ELearning \& Blended Learning sebagai Media Pembelajaran Bagi Guru dan Siswa di SMK Negeri 1 Bangkinang. Jurnal Pengabdian UntukMu NegeRI, 2(1), 17-20.

[15] Azhar, K. A., \& Iqbal, N. (2018). Effectiveness of Google Classroom: Teachers' Perceptions. Prizren Social Science Journal, 2(2), 52-66.

[16] Dewi, A. S., Isnani, I., \& Ahmadi, A. (2019). Keefektifan Model Pembelajaran Stad Berbantuan Media Pembelajaran Terhadap Sikap Dan Kemampuan Pemecahan Masalah Matematika. JIPMat, 4(1). 7-11.

[17] Dewi, E. R. (2018). Metode Pembelajaran Modern Dan Konvensional. Jurnal Ilmu Pendidikan Dan Pembelajaran, 2(1), 44-52 